Military Technical College

Kobry El-Kobbah,

Cairo, Egypt.

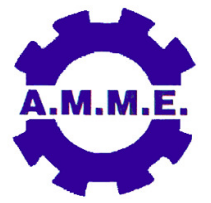

$17^{\text {th }}$ International Conference

on Applied Mechanics and

Mechanical Engineering.

\title{
STUDY OF MECHANICAL VIBRATION ON STRUCTURE AND PROPERTIES OF Mg-9AI ALLOY DURING SOLIDIFICATION
}

\author{
V. Chaturvedi ${ }^{1}$ and U. Pandel ${ }^{2}$
}

\begin{abstract}
In the present era, in automotive, aerospace, electric and communication industries AZ91 Mg alloys are extensively being used and it would increase if their strength and castability were improved. Mg- Al alloys have large freezing range, so is susceptible to the formation of coarse grained structure. Magnesium alloys are therefore dealt with grain refinement. Refinement of microstructure can be done either by chemical method in which grain refiners are added to refine the microstructure or by vibrations, where vibrations are imposed on solidifying melt. The various techniques to impose vibrations are; mechanical vibrations, electromagnetic vibrations and ultrasonic vibrations. In this paper, the effect of mechanical vibration on the microstructure and mechanical properties during solidification of $\mathrm{Mg}$ - 9Al alloy was investigated. This was tested in the frequency range from 0 to $40 \mathrm{~Hz}$ at constant amplitude $3 \mathrm{~mm}$. Mechanical tests such as tensile test, hardness test were carried out on the samples. It was concluded that on increasing the frequency of mechanical vibration during solidification refines microstructure and improves mechanical properties.
\end{abstract}

\section{KEY WORDS}

Mg- 9AI magnesium alloy, mechanical vibration, microstructure, tensile test, $\%$ elongation, hardness

1 PhD Scholar, Dept. of Met. and Mat. Eng. MNIT Jaipur, India

2 Professor, Dept. of Met. and Mat. Eng. MNIT Jaipur, India 


\section{INTRODUCTION}

Magnesium alloys have found major applications in automobiles, electronics, aerospace and aircraft industries. Since they have low tensile strength and ductility, poor cold formability and inferior resistance to corrosion and oxidation, the application of magnesium is limited as a structural material. Specific strength and specific stiffness of materials and structures play a vital role in the designing of weight saving components. Therefore, especially components for automotive bodies require importance of weight saving, where energy consumption and power restrictions are a major concern [1]. Recently, because of the fine grained structure of the wrought magnesium alloys reported to be superior to those of cast magnesium alloys [2, 3].

The primary problem is that the developed dendrites are always yielded in normal castings because the alloy has a large freezing interval, in which a constitutionally under cooled region can be readily produced and thus to form dendrites. Therefore, suppression of formation of coarse dendrites is a key issue in improving the alloy properties. Various researchers have seen that the aforementioned defects can be overcome by microstructural refinement or through the morphological modification from dendrite grains to spherical ones through different types of vibrations during solidification of metals and alloys. During solidification the induced vibration usually lead to grain refinement, improve fluidity, and reduction of the concentration of the dissolved gases [4,5] resulting in the improvement of mechanical properties. As there are three ways of inducing vibrations: ultrasonic vibrations, electromagnetic vibrations and mechanical vibrations, but here only mechanical vibrations are used to observe the effects on mechanical properties. Also there is no need of large or special device in mechanical vibration and can be easily imposed [6] also it is the most promising method of applying vibrations to solidifying the melts due to its simplicity and the ruggedness of the equipment needed for introducing vibration.

\section{EXPERIMENTAL PROCEDURE}

\section{Materials and Sample Preparation}

The AZ91 magnesium alloy (with a nominal composition of Mg-9 wt\% Al- 1mass\% $\mathrm{Zn}$ ) was treated by mechanical vibrations. The AZ91 Mg alloy was prepared by using ingots of pure $\mathrm{Mg}(99.95 \%)$, pure $\mathrm{Al}(99.99 \%)$, and pure $\mathrm{Zn}(99.9 \%)$.

Figure 1 shows the experimental set up. The elements were kept in a steel crucible in a bottom pouring furnace in an argon atmosphere and under proper flux cover $\left(\mathrm{MgCl}_{2} \cdot \mathrm{MgO} . \mathrm{CaCl}_{2} \cdot \mathrm{NaCl}\right)$ to coagulate and separate the slag from the melt. The stainless steel mold with a preheated temperature of $160^{\circ} \mathrm{C}$ was transferred to the heat-preserving furnace and then the melt was poured into stainless steel mold for mechanical vibration. The amplitude was kept constant $3 \mathrm{~mm}$ while the frequency was varied for three times i.e., 31, 35 and $40 \mathrm{~Hz}$. Experimental parameters are given in Table 1. 


\section{RESULTS AND DISCUSSIONS}

\section{Microstructure}

The microstructure of as cast AZ91 magnesium alloy is composed of $\alpha-\mathrm{Mg}$ matrix, divorced eutectic $\beta-\mathrm{Mg}_{17} \mathrm{Al}_{12}$ phase and secondary precipitated $\beta-\mathrm{Mg}_{17} \mathrm{Al} \mathrm{l}_{12}$ phase. $\beta$ $\mathrm{Mg}_{17} \mathrm{Al}_{12}$ got distributed in $\mathrm{Mg}$ matrix during the crystallization process. Coarse dendrites of the primary phase $(\alpha-M g)$ are formed throughout the alloy and the eutectic $\beta-\mathrm{Mg}_{17} \mathrm{Al}_{12}$ phase appeared on the grain boundaries in as cast alloy. However, on imposing the vibrations to the melt, a uniform distribution of the fine grains of the primary $\alpha-M g$ phase was achieved, and a dense network-like eutectic $\beta$-phase solidified. Also, the precipitation of $\alpha-M g$ dendrites releases latent heat, which causes an increase of the melt temperature ahead of the solidification interface and decreases the degree of super-cooling that suppresses the growth of $\mathrm{a}-\mathrm{Mg}$ dendrites, leading to the grain refinement.

\section{Mechanical Properties}

\section{Tensile tests}

The tensile tests of non- treated and mechanically vibrated treated AZ91 magnesium alloys is shown in Fig.3.1 and Fig.3.2. It can be seen that the tensile strength and the elongation are increased markedly with the mechanical vibration treatment.

\section{Hardness}

Figure 4 shows that the hardness is also increasing as the frequency has been increased. Maximum hardness is at frequency $40 \mathrm{~Hz}$. This could be explained that the structures of the Mg-Al-Zn alloys consist of a solid solution and the intermetallic compound $\mathrm{Mg}_{17} \mathrm{Al}_{12}$ ( $\beta$ phase), at the grain boundaries the quantity and character of these intermetallic compounds greatly influence the mechanical properties of the component. The compound $\mathrm{Mg}_{17} \mathrm{Al}_{12}$, as the phase solidifying last, fills interdendritic cavities and thus influences flowability, shrinkage, porosity, and the development of cracks. The strength and elasticity properties of the alloys depend on the character of the intermetallic phases.

\section{CONCLUSIONS}

- The resulting microstructures of all the investigated alloy samples showed that the vibrations affect the microstructure. Coarse dendrites of the primary phase $(\alpha-\mathrm{Mg})$ were formed throughout the alloy, and the interdendritic eutectic $\beta$-phase $\left(\mathrm{Mg}_{17} \mathrm{Al}_{12}\right)$ appeared on the grain boundaries without the mechanical vibration pretreatment. However, by applying frequency to the melt, a uniform distribution of the fine grains of the primary $\alpha-M g$ phase was achieved, and a dense network-like eutectic $\beta$-phase solidified.

- The tensile strength of the alloys is found to be affected as a result of imposition of vibrations. With the increase in the frequency of vibration, increase in the tensile strength has been found. 
- Hardness of the alloys also increased with the increase in the frequency. The alloy with the maximum frequency was found to have greater Brinell hardness number than the alloys of lower frequency and without frequency.

\section{REFERENCES}

[1] Tkachenko VG, Maksimchuk IN, Volosevich PY, Lashuk NK, Malka AN, Friezel VV Creep resistance and long-term strength of structural magnesium alloys. High Temp Mater Proc 25 (1-2):97-107 (2006).

[2] Fisher T.P., British Foundryman Vol. 66, no. 3, pp 71- 84 (1973).

[3] Dommaschk C., Ph.D. Thesis, University of Freiberg, Germany (2003).

[4] J. Campbell: International Metal Reviews, vol.26, pp. 71 (1981).

[5] E.A. Hiedemann: The Journal of the Acoustical Society of America vol.26, pp. 831 (1954).

[6] Naoki Omura, Yuichiro Murakami, Mingjun Li, Takuya Tamura, Kenji Miwa, Hideki Furukawa, Masayuki Harada, and Mitsuyoshi Yokoi, "Effects of Mechanical Vibration on Macrostructure and Mechanical Properties of AC4C Aluminum Alloy Castings," Materials Transactions, vol. 50, no. 11, pp. 2578 to 2583, (2009).

[7] Deshpande Jayesh, "The effect of mechanical mold vibration on the characteristics of aluminum alloys, "pp.21 (2006).

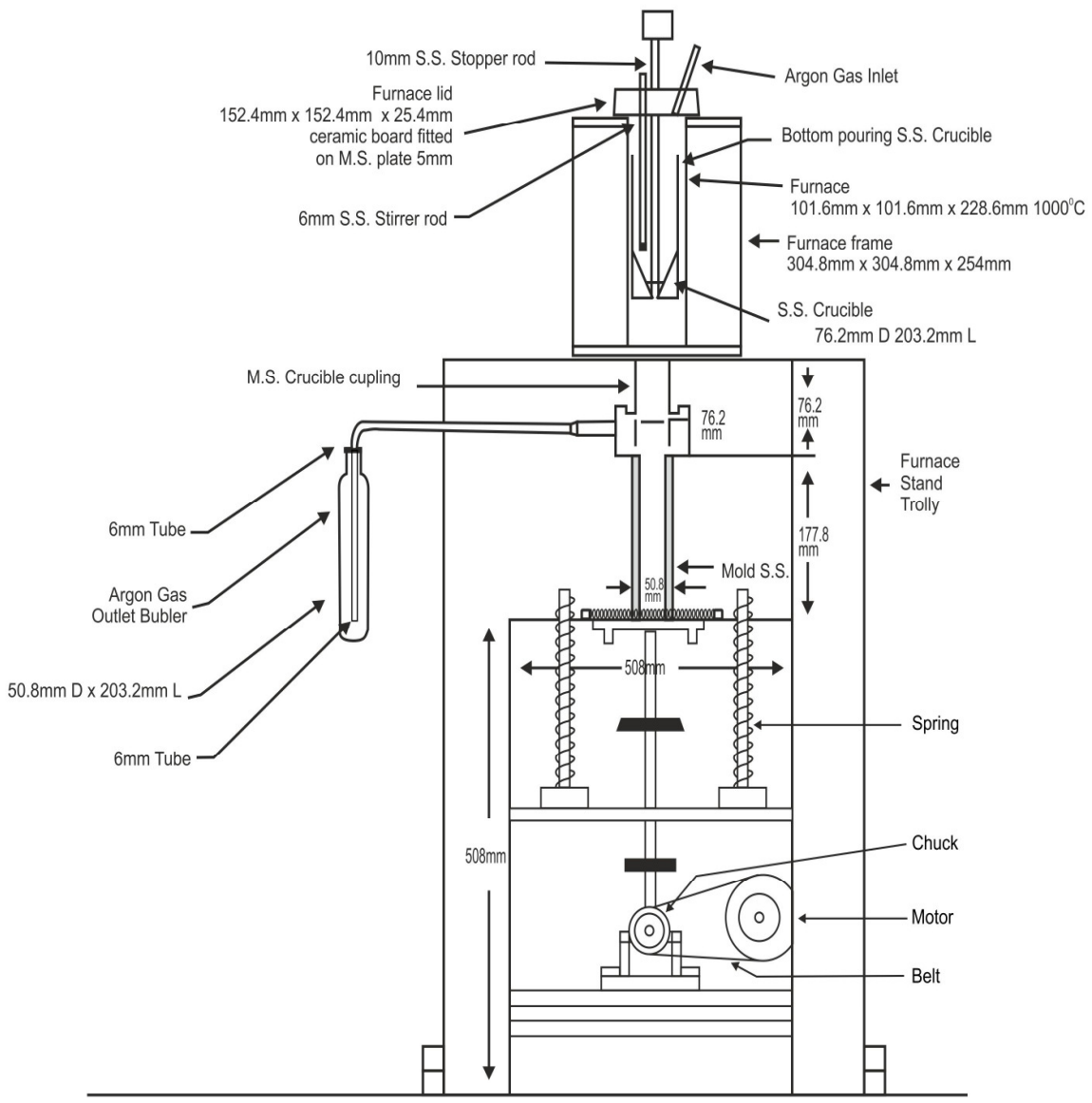

Fig.1. Experimental Set Up. 


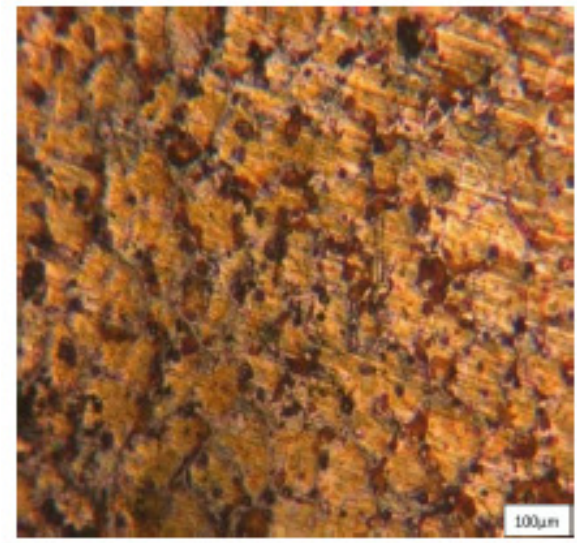

(a)

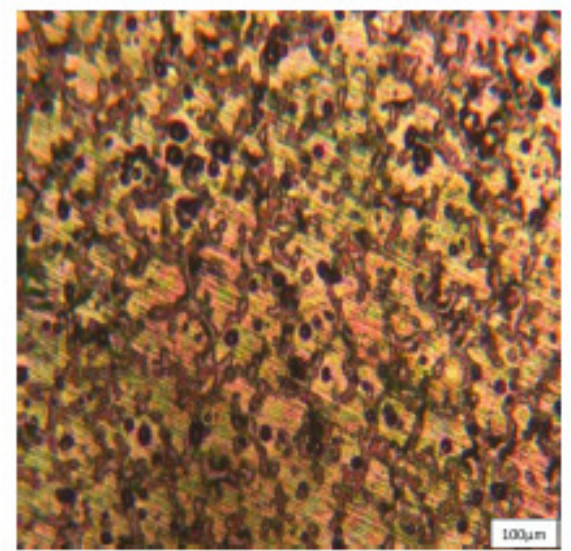

(c)

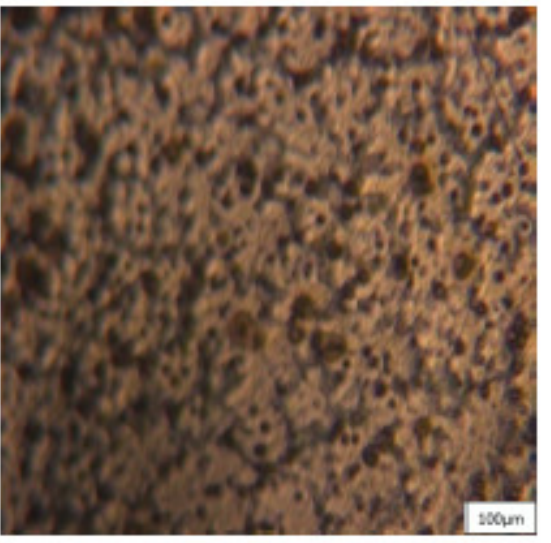

(b)

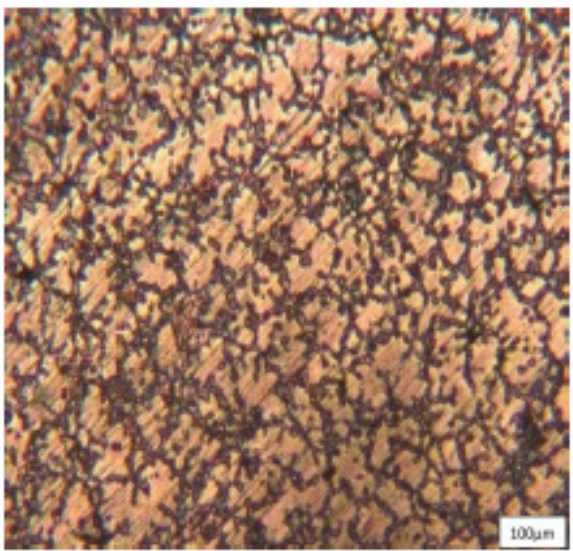

(d)

Fig.2. Microstructures of specimens obtained at 100X with frequencies (a) as cast (b) $30.90 \mathrm{~Hz}$ (c) $35.16 \mathrm{~Hz}$ (d) $40.25 \mathrm{~Hz}$ at constant amplitude 3

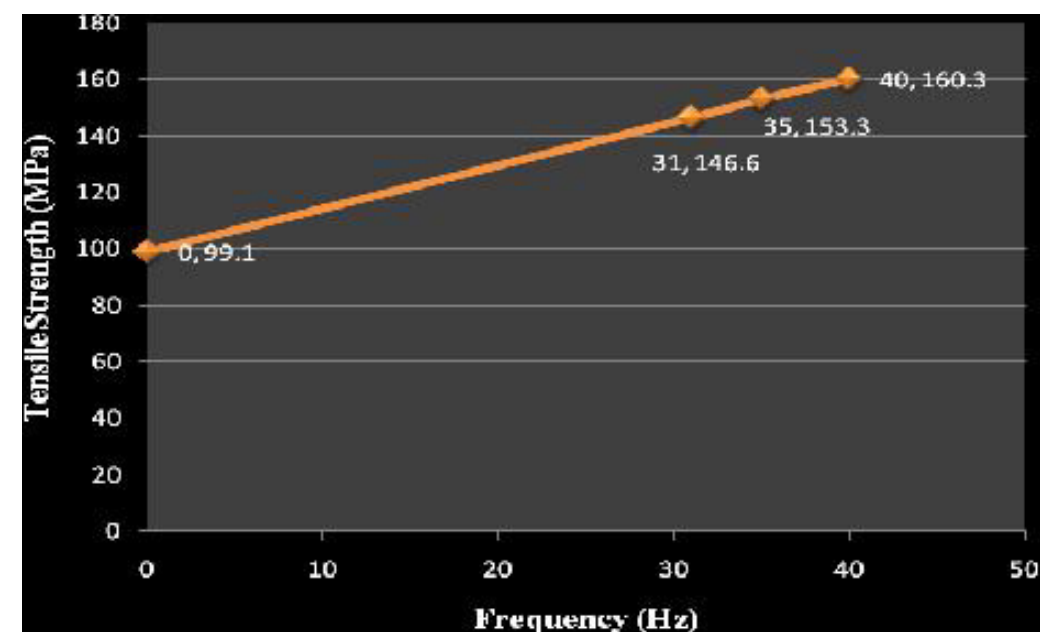

Fig. 3.1. Relation between the frequencies of vibration and Ultimate Tensile Strength of the samples. 


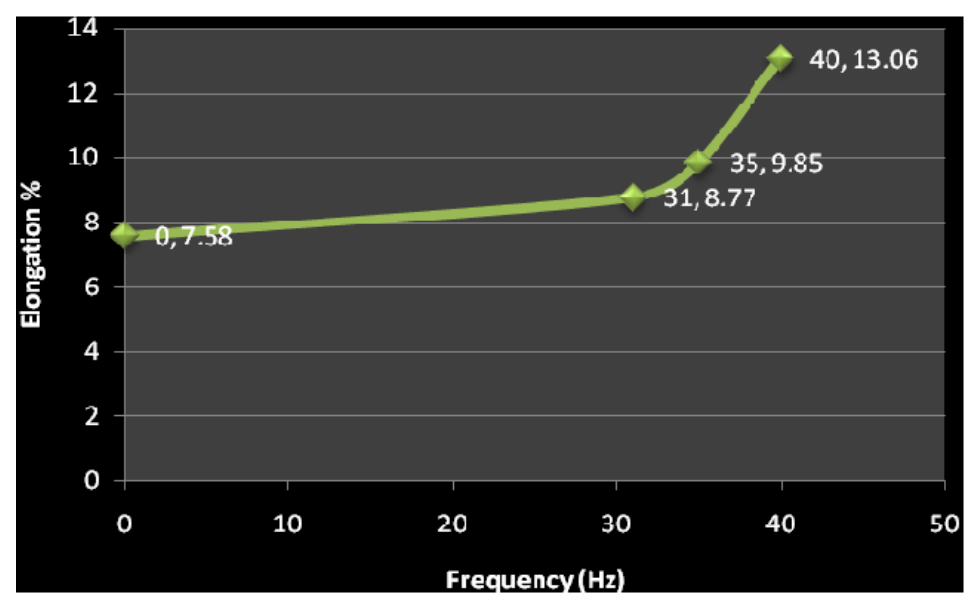

Fig. 3.2. Relation between the frequencies of vibration and \% elongation of the samples.

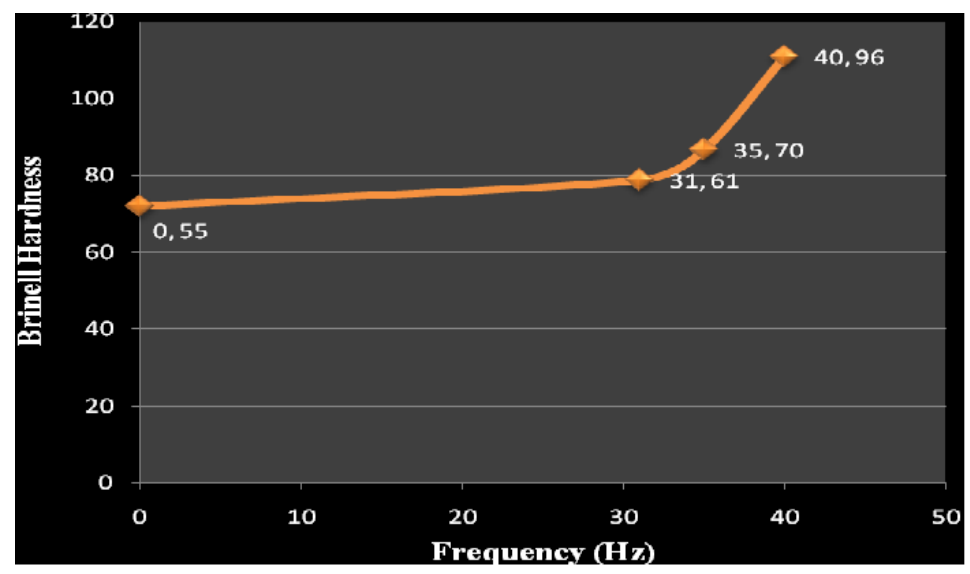

Fig. 4 Effects of frequency of vibration on the hardness of the samples. 
Table 1. Experimental parameters.

\begin{tabular}{|c|c|c|c|}
\hline S.No & $\begin{array}{c}\text { Frequency } \\
(\mathbf{H z})\end{array}$ & $\begin{array}{c}\text { Amplitude } \\
(\mathbf{m m})\end{array}$ & $\begin{array}{c}\text { Pouring } \\
\text { Temperature } \\
\left({ }^{\circ} \mathbf{C}\right)\end{array}$ \\
\hline 1. & - & - & $700-740$ \\
\hline 2. & 31 & 3 & $700-740$ \\
\hline 3. & 35 & 3 & $700-740$ \\
\hline 4. & 40 & 3 & $700-740$ \\
\hline
\end{tabular}

Table 2. Results of various mechanical properties at constant amplitude and different frequencies of mechanical vibration

\begin{tabular}{|c|l|l|l|}
\hline $\begin{array}{c}\text { Frequency } \\
\text { (Hz) }\end{array}$ & \multicolumn{1}{|c|}{$\begin{array}{c}\text { \% } \\
\text { Elongation }\end{array}$} & $\begin{array}{c}\text { UTS } \\
\text { N/mm2 }\end{array}$ & BHN \\
\hline 0 & 7.58 & 99.1 & 55 \\
\hline 31 & 8.77 & 146.6 & 61 \\
\hline 35 & 9.85 & 153.3 & 70 \\
\hline 40 & 13.06 & 160.3 & 96 \\
\hline
\end{tabular}

